\title{
Editorial de honra
}

\author{
Motivations for doing scientific research
}

David Christopher Watts

\author{
"I don't get out of bed for less than \$10,000 a day." - Linda Evangelista, Canadian Model. \\ "Great are the works of the Lord; they are pondered by all who delight in them". - Psalm 111:2
}

Motivation is literally the desire to do things. As a theoretical construct it represents the reasons for people's actions, desires and needs. But motivations can be deeply buried within our consciousness such that we may rarely subject them to analysis, even though they have their impact day by day. I am thinking here specifically about the motivations for research as a scientist, not only at the 'early career' stage of working towards a $\mathrm{PhD}$ degree, but also in the 'mid career' or 'long term' stages of lifelong engagement with the scientific enterprise.

Perhaps if I was a neuroscientist I might have discovered a scientific reason for doing research. For some people I know, science is everything and they acknowledge no realm outside its comprehensive boundaries. However, as things stand, I expect to discover such motivation from outside science itself. Certainly, I know that my wife loves me, but not for any scientific reason! So also, I suggest, there are extra-scientific factors to be identified that can motivate us scientifically.

Much depends, of course, on exactly what we mean or envisage by the terms science or scientist. In most European languages derived from Latin, the word science is essentially the same, but in German, Wissenshaft has a broader meaning, including humanities subjects such as history, law and philosophy. Perhaps we would all be comfortable with the following definition:

"Science is the intellectual and practical activity encompassing the systematic study of the structure and behavior of the physical and natural world through observation and experiment".

The English philosopher and historian of science William Whewell invented the term scientist in 1833. His suggestion of the term was partly satirical, a response to changing conceptions of science itself in which natural knowledge was increasingly seen as distinct from other forms of knowledge. Until the late $19^{\text {th }}$ or early $20^{\text {th }}$ century, scientists were called "natural philosophers". There is much to recommend this term, as philosophy is literally a 'love of wisdom' - hence natural philosophy is 'a love of wisdom about natural things'. If we consider motivations to acquire and develop such a love, they become closer to basic human concerns and potentially involve greater proportions of people in this quest, not only 'professional scientists'. My friend, Professor Tom McLeish FRS of the University of Durham, has developed this theme extensively in his recent book: Faith and Wisdom in Science ${ }^{1}$.

In the short term, there are some obvious pragmatic social factors that motivate graduate students in scientific research. The $\mathrm{PhD}$ degree is not only a passport to a scientific career but a qualification highly regarded in society and by many employers, such that it could become a 'meal ticket' for life, especially for those who also possess a clinical qualification. So, even if scientific research is not your long-term career plan, spending unsocial hours in the laboratory, studying scientific papers and writing that thesis is a good investment if you have the talent and the opportunity. Those fortunate to work with a good supervisor and alongside other $\mathrm{PhD}$ candidates can enjoy the group camaraderie - if the competitive atmosphere is not too stressful! Moreover, the disciplines of conducting research, a proven ability to address a major scientific challenge and to communicate results are invaluable transferrable skills. They also should boost your self-confidence at many levels. There is a huge sense of relief on completing a $\mathrm{PhD}$ thesis and in satisfying the examiners. However, for most of us, it is just the start of a lifetime of hard work in any area of employment! But the ability to earn a living, and perhaps support a family or other dependents, remains an eminently worthy motivation, as is the contribution we can make to society through scientific enquiry. 
When it comes to longer-term scientific research, additional motivations may become necessary. For many scientists these are also pragmatic, including the desire to build a career in academia or industry and, with it, an international reputation, especially through publications and conference presentations. Along the way there can be many disappointments and setbacks: experiments that fail to work; grant applications unfunded; papers rejected by journals; problems of mentoring suitable students; even academic rivalries! In fact, significant personal qualities are needed including patience, perseverance and practical wisdom in dealing with all kinds and conditions of people. The fictional detective, Sherlock Holmes, is quoted as saying: "Genius is an infinite capacity for taking pains" some authors would take more pains over the detailed preparation of the manuscripts they submit! Any substantial paper that I am involved in writing has to go through about 20 successive versions, before the mistakes and typos are eliminated and it reads as clearly as possible.

Especially for scientists researching topics related to healthcare, a significant motivation is working towards ultimate patient wellbeing. This can help displace egocentric motivations through concern for the welfare of others. Healthcare relatedness can be direct or indirect, proximate or distant. In the nature of the case, some of the greatest benefits arise through 'pure' research. An example of this is the invention of blue light-emitting diodes (LEDs), for which the 2014 Nobel Prize in Physics was awarded. These now have widespread applications to clinical photo-polymerization in dentistry. It is to be regretted that much government-funded research in the UK requires advance specification of benefits to end-users.

Healthcare applications emphasize the social importance of science and its spin-offs in technology. However, what can motivate the scientist to persist in his or her researches over many decades of a career? Here it becomes even more important to draw upon the deepest levels of motivation. An essential quality in a scientist is an enquiring mind. Michael Faraday, one of my scientific heroes from the $19^{\text {th }}$ Century, is amongst the greatest experimental researchers of all time in both chemistry and physics. When the Chancellor of the Exchequer - the top government finance minister - visited Faraday's lab, he asked: "Mr Faraday, of what possible use is electricity?" Faraday replied: "Sir, one day you will be able to tax it"! Faraday was a pioneer in what physicists now call field theory, by which he conceptualized how electric charges or magnetic poles mutually interact in space. Faraday was also an outstanding science communicator. He said, with reference to his lectures on combustion to young audiences at the Royal Institution in London: "God give them brains to be surprised!"”.

Possession of an enquiring mind generates good scientific questions. In fact, an ability to ask original questions is more important than knowledge of the answers to previous questions. This is the great educational transition upon moving from being an undergraduate student - where most courses are taught - to becoming a graduate research student. You raise a question, but find the answer is not in the textbooks; that is what makes it research! You have to discover it by the right mix of theoretical thought, combined with experimental verification.

Sooner or later, your enquiring mind may start to ask more basic questions. Why do scientific laws exist? Is there a lawgiver? Why do they take the form that they do? Why are there many 'inverse square' laws, rather than 'inverse cube' laws? You may grapple with the question posed by the Nobel scientist Eugene Wigner, as to why mathematics is so 'unreasonably effective' in science'. Then there is the point expressed by Albert Einstein: "the most incomprehensible thing about the universe is that it is comprehensible"

These questions actually take us across the line from the specific sciences to the philosophy and theology of science. As Einstein again expressed $i^{6}$ :

Science can only be created by those who are thoroughly imbued with the aspiration towards truth and understanding. This source of feeling, however, springs from religion. To this there also belongs the faith in the possibility that the regulations valid for the world of existence are rational, that is, comprehensible to reason. I cannot imagine a scientist without that profound faith. This situation may be expressed by an image: science without religion is lame, religion without science is blind.

In my own scientific career, religious motivation - and specifically Christianity, has played a major role, which I have recently described in some detail, elsewhere ${ }^{7}$. Amongst numerous other factors, the healthcare motivations for science arise as a natural outcome of the healing ministry of Jesus of Nazareth. It is no coincidence that since 1886 the Royal Eye Hospital in my native city of Manchester has carried a striking mural depicting Jesus healing a man born blind ${ }^{8}$. 


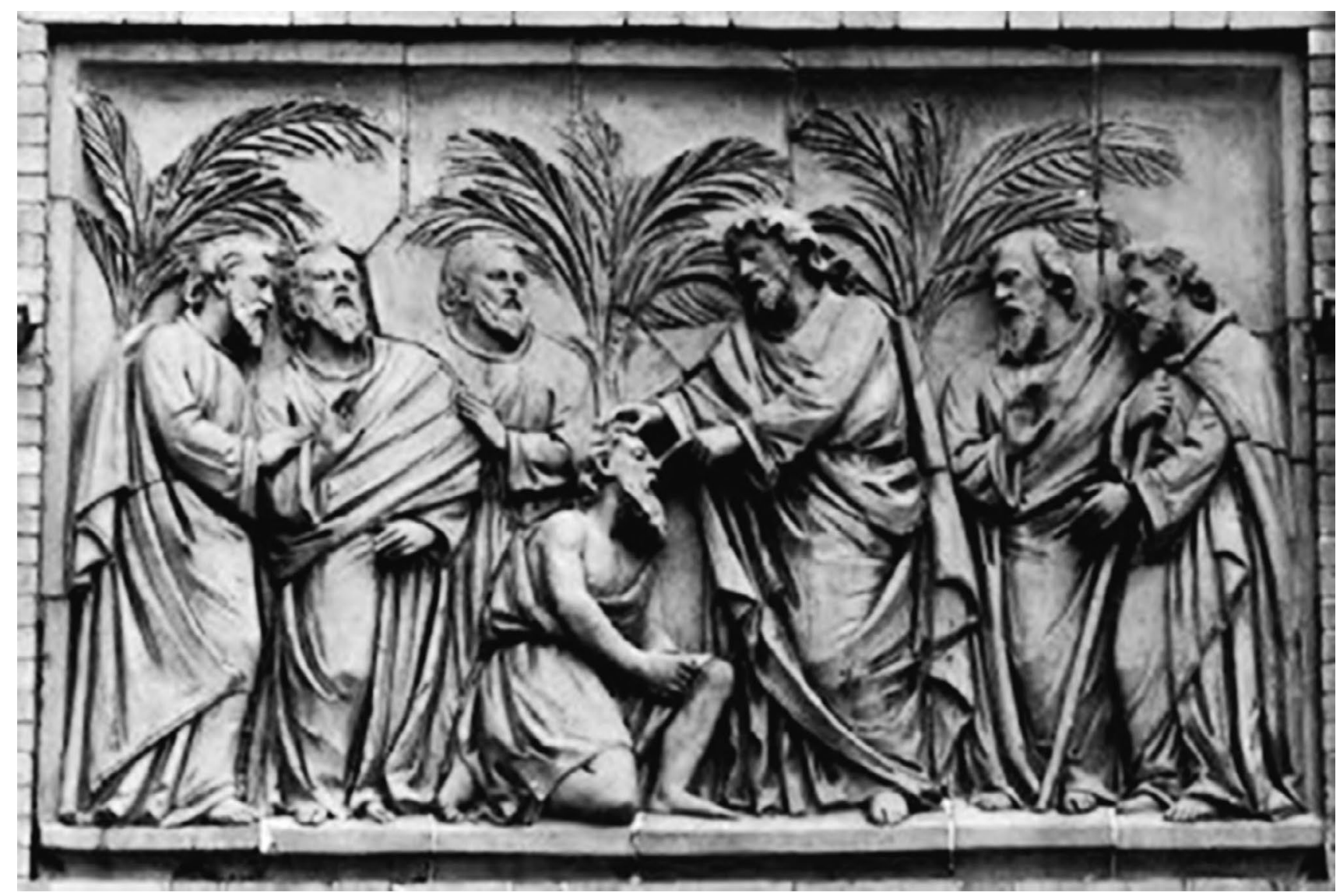

In the United Kingdom, there is a flourishing organization called Christians in Science (www.cis.org. uk), which provides strong motivations for scientific research. We recently hosted a conference in Manchester on the theme 'God loves Science!' . Similarly, at the University of Cambridge, there is a sister organization: The Faraday Institute for Science and Religion, (www.faraday.st-edmunds.cam.ac.uk ). Both of these organizations have good international links, particularly with Brazil (www.cristaosnaciencia.org.br). The interaction between Science, Technology and Religion is not only an interesting academic topic, but also a relevant theme with implications in our everyday life.

Scientific research focuses upon the nature of underlying causes for phenomena. This is illustrated in a famous engraving ${ }^{10}$, within which the representative 'scientist' figure is not content merely to view the visible phenomena of sun, moon and stars, but wants to look beyond to the underlying mechanisms.

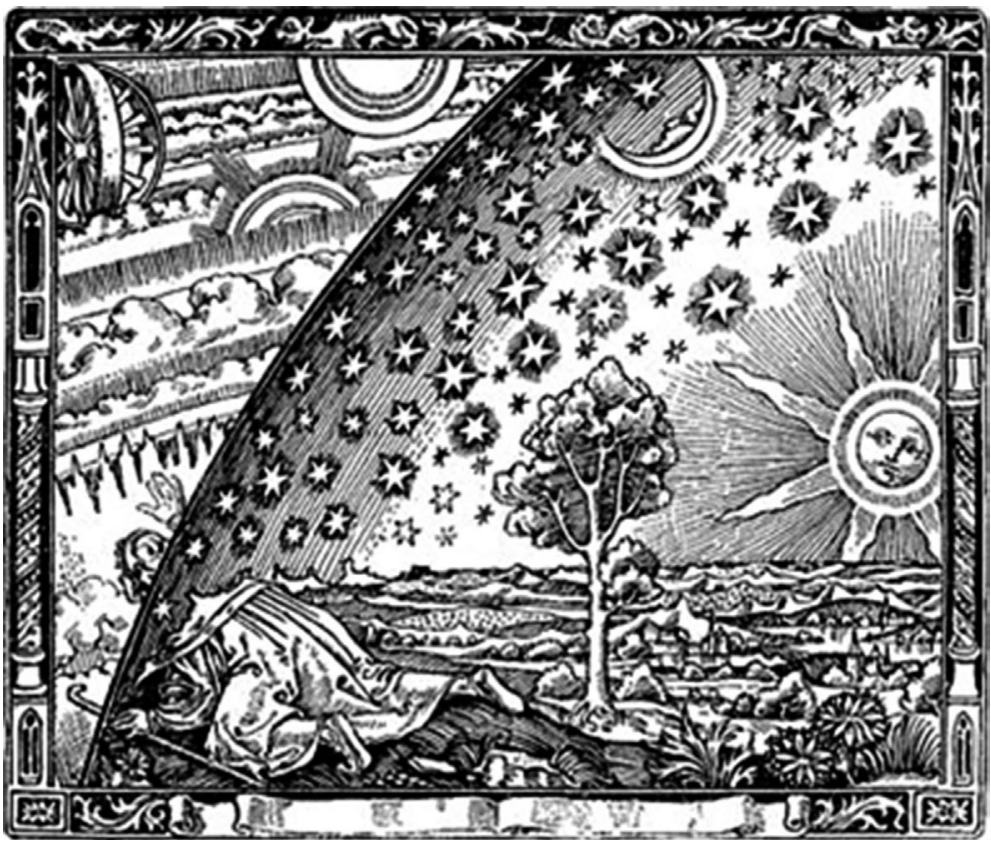

Contemporary science has gradually developed a hierarchically organized set of structural levels of analysis of the physical, chemical and biological world. For example, all chemicals are composed of a set of elements. The atoms of each element consist of a nucleus and electrons in quantum orbitals. The nucleus of each atom has an inner structure, etc.

Some scientists make the mistake of thinking that some particular level of analysis is fundamental - perhaps the four ultimate physical forces and their carrier 'particles' or bosons.

This sequential breakdown of complex physical reality to simpler elements is a perfectly valid strategy, within science, but it is not the only approach necessary to give a balanced or 
complete understanding. Misuse of this approach arises when some scientists say, for example, that human beings are 'nothing but' atoms and molecules and thereby adopt an exclusively materialist philosophy. When we consider the inverse approach of combining simpler elements to form more complex structures, we find that additional - emergent - properties arise. For example, the characteristic features of water, including wetness, are not properties of individual water molecules but of assemblies of multiple billions of water molecules.

The materialist philosophy, with its resolutely pessimistic outlook, is probably the leading alternative to a theistic understanding of reality, as expressed for example in Christian Theism - the religion with the strongest possible emphasis upon the goodness and value of the material world. Theism also promotes great appreciation for beauty in science, coupled with attitudes of wonder and gratitude to the Creator of the universe. As we look through a telescope or microscope more and more amazing details come into view. Theism embodies convictions that human existence has ultimate purpose and value, including that aspect of human culture that we call the scientific enterprise. Human beings are predisposed to favor activities that have a long-term purpose and so a theistic (God-centered) understanding of human existence and destiny is the ultimate motivator for scientific enquiry.

\section{References}

1. T. McLeish, (2014): Faith and Wisdom in Science, Oxford: University Press. ISBN: 9780198702610

2. Arthur Conan-Doyle, A Study in Scarlet.

3. M. Faraday (1861): in W. Crookes (Ed.), A course of six lectures on The chemical history of a candle, Griffin, Bohn \& Co., London Full text of The chemical history of a candle from Project Gutenberg.

4. Eugene Wigner, (1960): The Unreasonable Effectiveness of Mathematics in the Natural Sciences. Communications on Pure and Applied Mathematics 13: 1-14.

5. Albert Einstein, (1936): 'Physics and Reality', in Ideas and Opinions; trans. Sonja Bargmann (New York: Bonanza, 1954 ), p292.

6. Max Jammer, (1999): Einstein and Religion, Princeton: University Press, p. 94.

7. DC Watts (2014): Discovering unexpected dimensions of the divine plan; Chapter 15 in (R.J. Berry, ed): Christians and Evolution. pp. 260-275. Monarch. ISBN: 9780857215246.

8. The Gospel According to St John: chapter 9.

9. www.nazarene.ac.uk/god-loves-science-notes-and-reports/

10. The Flammarion engraving: en.wikipedia.org/wiki/Flammarion_engraving 